Article

\title{
Preparation of ZnO Nanoparticle/Acrylic Resin Superhydrophobic Coating via Blending Method and Its Wear Resistance and Antibacterial Properties
}

\author{
Changquan $\mathrm{Li}^{1,2}$, Chen Wang ${ }^{1}$, Ziang $\mathrm{Li}^{1}{ }^{1}$, Zhenjun Cao ${ }^{2}, \mathrm{YuXie}^{2, *} \mathbb{D}$, Mingshan Xue ${ }^{2}$ and Jinsheng Zhao ${ }^{3, * \mathbb{C}}$ \\ 1 School of Materials and Engineering, Jiangsu University of Technology, Changzhou 213001, China; \\ lichangquan@163.com (C.L.); wangchen@163.com (C.W.); liziang@163.com (Z.L.) \\ 2 College of Environment and Chemical Engineering, Nanchang Hangkong University, \\ Nanchang 330063, China; caozhenjun@163.com (Z.C.); xuemingshan@163.com (M.X.) \\ 3 College of Chemistry and Chemical Engineering, Liaocheng University, Liaocheng 252059, China \\ * Correspondence: xieyu_121@163.com (Y.X.); zhaojinsheng@lcu.edu.cn (J.Z.)
}

check for updates

Citation: Li, C.; Wang, C.; Li, Z.; Cao, Z.; Xie, Y.; Xue, M.; Zhao, J.

Preparation of $\mathrm{ZnO}$

Nanoparticle/Acrylic Resin

Superhydrophobic Coating via Blending Method and Its Wear

Resistance and Antibacterial

Properties. Materials 2021, 14, 3775.

https://doi.org/10.3390/ma14143775

Academic Editor: Ewa Popko

Received: 31 May 2021

Accepted: 1 July 2021

Published: 6 July 2021

Publisher's Note: MDPI stays neutral with regard to jurisdictional claims in published maps and institutional affiliations.

Copyright: (c) 2021 by the authors. Licensee MDPI, Basel, Switzerland. This article is an open access article distributed under the terms and conditions of the Creative Commons Attribution (CC BY) license (https:/ / creativecommons.org/licenses/by/ $4.0 /)$.

\begin{abstract}
Herein, a facile method for the preparation of an acrylic resin-based superhydrophobic coating is provided. Firstly, $\mathrm{ZnO}$ nanoparticles were modified with silane to obtain hydrophobic $\mathrm{ZnO}$, which was then homogeneously blended with acrylic resin. Subsequently, the mixture was sprayed on an aluminum sheet to form a cured coating. The surface composition and morphology of the coating were characterized using X-ray diffraction (XRD), Fourier transform infrared spectroscopy (FTIR), and scanning electron microscopy (SEM). The hydrophobicity, wear resistance, and antibacterial properties of the prepared samples were tested. The optimized hydrophobicity was achieved with $10 \mathrm{wt} \%$ modification agent and resin-to- $\mathrm{ZnO}$ mass ratio of 1:4, exhibiting contact and sliding angles of $168.11^{\circ}$ and $7.2^{\circ}$, respectively. Wear resistance was insufficient with a low resin content, while it grew with the increase in the resin content. However, when the resin content was excessively high, the hydrophobicity was reduced because the resin could wrap the modified ZnO nanoparticles and decrease the number of hydrophobic groups on the surface. Compared with the pure acrylic resin coating, the $\mathrm{ZnO}$ nanoparticle/acrylic resin superhydrophobic coating demonstrated a significant enhancement in the antibacterial properties.
\end{abstract}

Keywords: ZnO nanoparticle; acrylic resin; superhydrophobic coating; anti-biofouling; aluminum substrate

\section{Introduction}

Owing to their unique properties, superhydrophobic coatings can be used in selfcleaning [1-5], anti-corrosion [6-8], anti-icing [8-10], and oil-water separation [10-12], suggesting great potential in a broad range of applications [13-22]. ZnO nanoparticle (nano- $\mathrm{ZnO}$ ) has strong anti-bacterial properties because of its low volume and high surface activity [23-25]. Hsieh et al. [26] successfully prepared a superhydrophobic coating using a composite of $\mathrm{ZnO}$ and fluorinated polymer. Spasova et al. [21] reported the superhydrophobic surfaces composed of $\mathrm{ZnO}$ nanoparticles-containing polyvinylidene fluoride (PVDF) and polyvinylidene fluoride-hexafluoro propylene (PVDF-HFP) via the electrostatic spinning method [27]. Chemicals with low surface energies are commonly used in the preparation of hydrophobic materials, including siloxanes, fluorides, and long-chain alkanoic acids, which can form covalent bonds with nano-ZnO by breaking their chemical bonds and chains [28-30]. After this modification, the microstructure of nano-ZnO does not change and nano-ZnO becomes superhydrophobic while retaining its original semiconductor (optical, electric, and magnetic) properties. Guo et al. [31] prepared a transparent thin film composed of $\mathrm{ZnO}$-nanorod array using the hydrothermal method. Sakai et al. [32] fabricated a $\mathrm{ZnO}$ thin film on the Si substrate via the sol-gel method, and then obtained a superhydrophobic $\mathrm{ZnO}$ thin film after drying. 
Herein, a facile method for the preparation of an acrylic resin-based superhydrophobic coating is reported. Firstly, nano-ZnO was modified with organosilane to obtain hydrophobic nano-ZnO. The suspension of hydrophobic nano- $\mathrm{ZnO}$ was homogeneously blended with acrylic resin. Then, the mixture was sprayed onto an aluminum sheet to form a cured coating. The surface composition and morphology of the coating were characterized using X-ray diffraction (XRD), Fourier transform infrared spectroscopy (FTIR), and scanning electron microscopy (SEM). The effects of modifier content, mass ratio between acrylic resin, and nano- $\mathrm{ZnO}$ on the hydrophobicity of the samples were studied, and the wear resistance was measured. The potential applications of the coatings prepared in the present study may include the surface protection for marine vessels and offshore pipelines, and bottom protection for various marine facilities.

\section{Experimental}

\subsection{Preparation of Superhydrophobic Coatings}

The aluminum sheet $\left(50 \times 50 \times 50 \mathrm{~mm}^{3}\right)$ was sanded and polished with 600 -mesh sandpapers, rubbed five times from eight different directions every minute for $10 \mathrm{~min}$, followed by rinsing in de-ionized water for $1 \mathrm{~min}$. The acrylic acid primer and corresponding diluent (Changshu Fangta Paint Co. Ltd., Changshu, China) were mixed to form the suspension, as per the instructions. The as-polished aluminum sheet was placed in a fume hood for the spraying process. The primer mixture was loaded in the sprayer and the distance between the sprayer nozzle and aluminum sheet was maintained at $10 \mathrm{~cm}$ [33]. The duration for spraying was $1 \mathrm{~min}$ and the sprayed sheet was dried at room temperature for over $6 \mathrm{~h}$. The primer can enhance the binding strength, fullness, alkali resistance, and anti-corrosion, and ensure the homogeneous formation of an acrylic acid coating. The nano-ZnO (99.9\%, Beijing Huanqiujinding Tech Co. Ltd., Beijing, China) with sizes of $30 \mathrm{~nm}$ and $90 \mathrm{~nm}$ were mixed in the ratio of 1:1 and added into the solution of acetone (analytical reagent, Xilong Chemistry Co. Ltd., Shantou, China) and water (3:1 v/v), reaching a weight percentage of 3\%. Hexadecyltrimethoxysilane (HDTMS, chemical reagent, Shanghai Dibo Biology Tech Co. Ltd., Shanghai, China) of different weight $\%(2,4,6,8$, and $10 \%)$ was added as surfactant to nano- $\mathrm{ZnO}$ nanoparticles. The mixture was stirred using a magnetic stirrer and maintained at $60^{\circ} \mathrm{C}$ for $3 \mathrm{~h}$ to obtain a $\mathrm{ZnO}$ suspension. A suspension of acrylic topcoat (Changshu Fangta Coating Chemistry Co. Ltd., Changshu, China) and $\mathrm{ZnO}$ was prepared in the weight ratio of 0.5:2, 1:2, 1.5:2, 2:2, 2.5:2, and 3:2, as per instructions. After curing at room temperature for $30 \mathrm{~min}$, the nano- $\mathrm{ZnO}$ suspension was added into the topcoat suspension, and the mixture was stirred and ultrasonicated for $10 \mathrm{~min}$ before loading into the sprayer. After spraying on the primer layer for $1 \mathrm{~min}$, the coating was cured at room temperature for $6 \mathrm{~h}$ to obtain superhydrophobic nano-ZnO/acrylic resin composite coating. A schematic of the preparation process is presented in Figure 1.

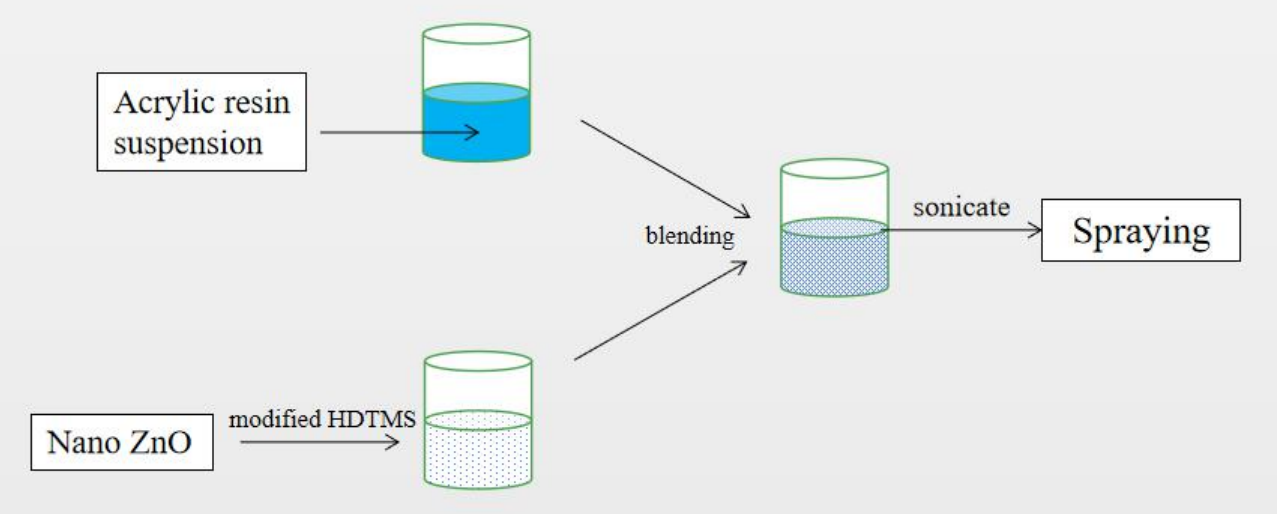

Figure 1. Flow chart of preparation of superhydrophobic coating of acrylic resin via the blending method. 
The surface modification mechanism of $\mathrm{ZnO}$ is demonstrated in Figure 2. After hydrolysis, the methoxyls of HDTMS were replaced by the hydroxyls. As the surface of $\mathrm{ZnO}$ particle has several hydroxyls, it can form hydrogen bonds with hydrolyzed HDTMS. By changing the reaction conditions, the hydrolyzed HDTMS can react with hydroxyls on the $\mathrm{ZnO}$ surface and dehydrate, forming a network structure. Meanwhile, $-\mathrm{CH}_{3}$ and $-\mathrm{CH}_{2}-$ hydrophobic groups were grafted onto the $\mathrm{ZnO}$ surface. These hydrophobic groups can largely enhance the stability and surface roughness, as well as the hydrophobicity.
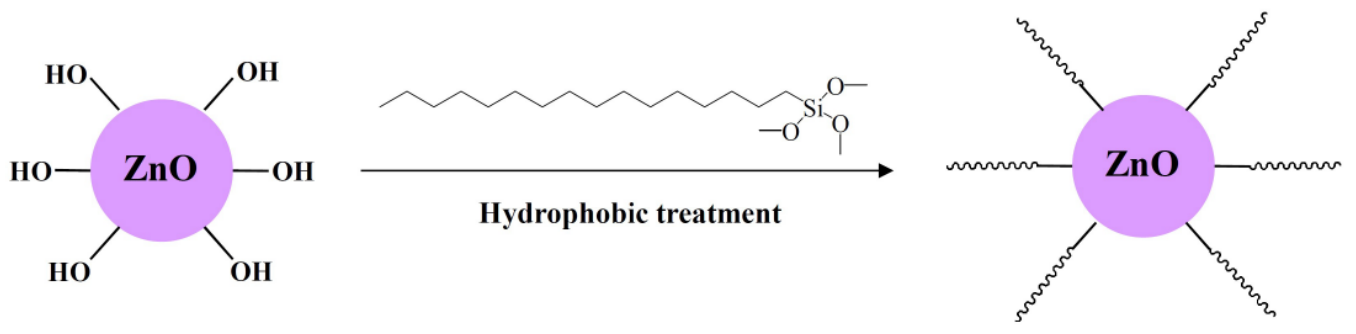

Figure 2. Surface modification mechanism of $\mathrm{ZnO}$.

\subsection{Structure and Morphology Testing and Characterization}

XRD was performed using an X-ray diffractomer (Bruker D8 ADVANCE, Bruker, Karlsruhe, Germany) with a Cu-K $\alpha$ source at the scan rate of $4^{\circ} \mathrm{min}^{-1}$ in the range of 20-80 . An environmental SEM (FEI Quanta 200, Thermo Fisher, Waltham, MA, USA) and field-emission SEM (FEI Nova Nano FE-SEM, Thermo Fisher, Waltham, MA, USA) were used in this study. The acceleration voltage was $15 \mathrm{kV}$ and the chamber was vacuumed during imaging. The molecular structure and chemical composition were characterized using a FTIR spectrometer (Bruker Vector 22, Bruker, Karlsruhe, Germany).

The hydrophilicity was characterized by measuring the contact and rolling angles using a contact angle meter (Krûss DSA20, Krûss Company, Hamburg, Germany). During the measurements, a small amount of water was dropped on the sample surface and the contact angle was measured with the meter. By flipping the sample stage, when the droplet rolled off, the rolling angle could be measured and recorded with the vernier angle caliper, as shown in Figure 3. $9 \mu \mathrm{L}$ of water was used for measurements and the average contact and rolling angles for each sample were averaged after five measurements.

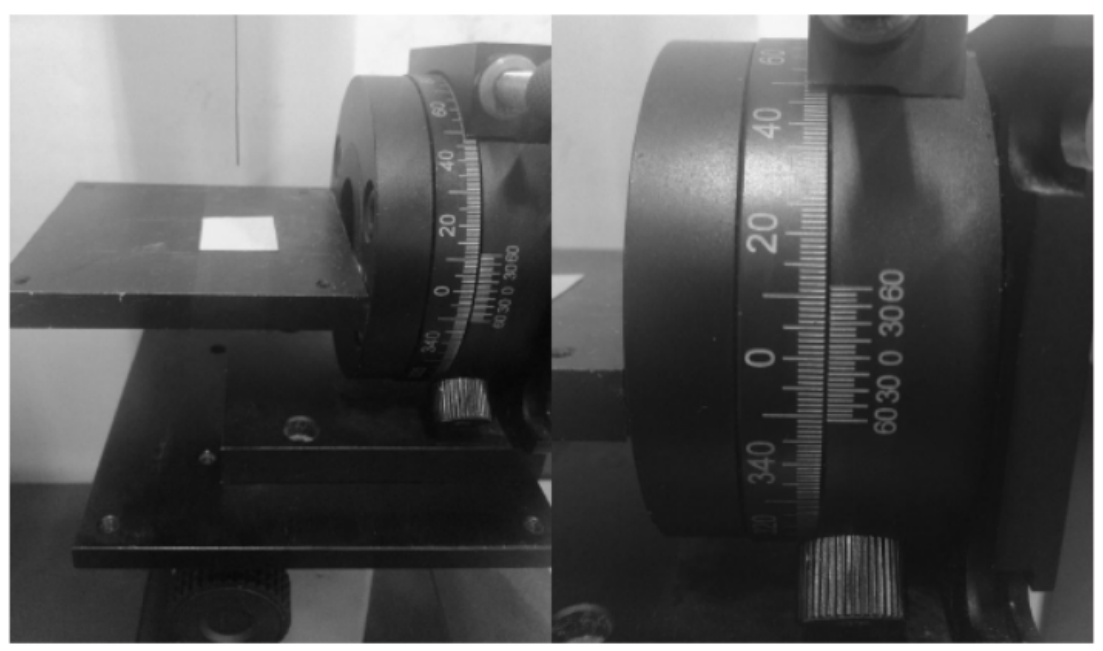

Figure 3. Test rotary table for rolling angle.

The measurement for wear resistance of the sample was performed by sanding the sample with a 220-mesh sandpaper, as shown in Figure 4 . The relative speed was $5 \mathrm{~cm} \mathrm{~s}^{-1}$, while the pressure was $1000 \mathrm{~Pa}$. The contact and rolling angles were recorded after sanding every five times. 


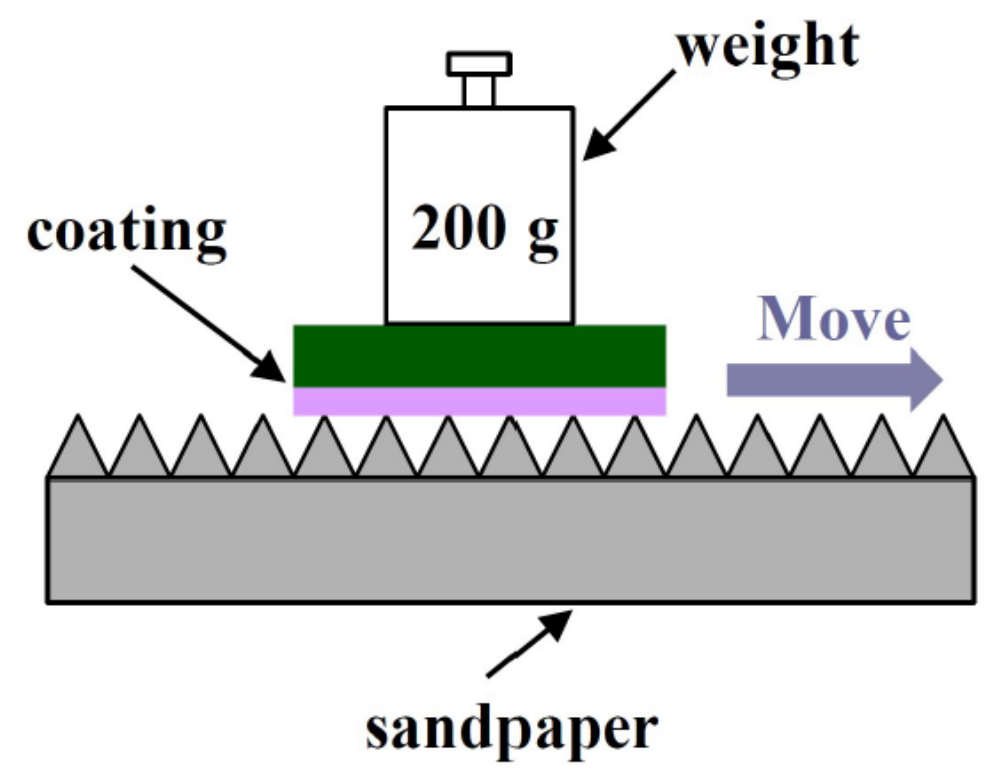

Figure 4. Schematic diagram of the anti-wear experiment.

\subsection{Antibacterial Testing}

\subsubsection{Specimen Preparation and Pretreatment}

The superhydrophobic samples and comparison samples (coated with pure acrylic resin) were cut into five identical $20 \times 20 \mathrm{~mm}^{2}$ specimens. The test results of five specimens were averaged. The surface was rinsed with $70 \mathrm{wt} \%$ ethyl alcohol, rinsed with de-ionized water for $5 \mathrm{~min}$, and then dried naturally.

\subsubsection{Bacteria Inoculation}

The superhydrophobic samples and comparison samples were used for the test. The gram-positive bacteria $S$. aureus was used as the testing bacteria. The agar medium for the test consisted of peptone $(5 \mathrm{~g})$, beef extract $(3 \mathrm{~g})$, and sodium chloride $(5 \mathrm{~g})$ in $1000 \mathrm{~mL}$ distilled water with a $\mathrm{pH}$ value of 7 . Finally, agar ( $15 \mathrm{~g})$ was added to the solution. The medium was sterilized in a autoclave for $30 \mathrm{~min}$ under a pressure of $7.0 \mathrm{~kg}$. The standard conditions of $106 \mathrm{CFU} / \mathrm{mL}$ (colony forming unit/mL) was utilized for antibacterial assay. This medium was transferred into sterilized Petri dishes. The bacteria species $(50 \mu \mathrm{L})$ cultures were spread on the solid surface of the media after solidification of the media. Over this inoculated petri dish, small pieces of the samples and untreated samples were placed and incubated for two days at $37^{\circ} \mathrm{C}$ in an incubation chamber to observe the inhibition zone. All the experiments were performed in triplicate to confirm their reproducibility.

\subsubsection{Colony Count}

The inoculated samples were eluted after culturing and the elution was transferred in an Erlenmeyer beaker. After stirring and diluting, the elution was transferred to Petri dishes to inoculate bacteria. The Petri dishes were placed in an incubator for $24 \mathrm{~h}$ before counting colonies.

\subsubsection{Antibacterial Rate Calculation}

The antibacterial rate was calculated from Equation (1):

$$
R=\frac{A-B}{A} \times 100 \%
$$

where $R$ is the antibacterial rate, $A$ is the colony number for the comparison sample after a $24 \mathrm{~h}$ of incubation time, and $B$ is the colony number for the superhydrophobic sample after a $24 \mathrm{~h}$ of incubation time. 


\section{Results and Discussion}

\subsection{FTIR Analysis}

The FTIR spectra of nano- $\mathrm{ZnO}$ and modified nano- $\mathrm{ZnO}$ are shown in Figure 5, respectively. Absorption peaks in the range of $1088.1 \mathrm{~cm}^{-1}$ can be observed in both the spectra, which is caused by the stretching and bending vibrations of hydroxyls or bridged hydroxyls on the surface of nano- $\mathrm{ZnO}$. In the ambient environment, water molecules can be adsorbed by the surface of nano- $\mathrm{ZnO}$, which can then decompose to form these adsorbed hydroxyl groups. The absorption peaks at 878.8 and $1386.5 \mathrm{~cm}^{-1}$ are the characteristic and vibration peaks of $\mathrm{Zn}-\mathrm{O}$ bonds, respectively.

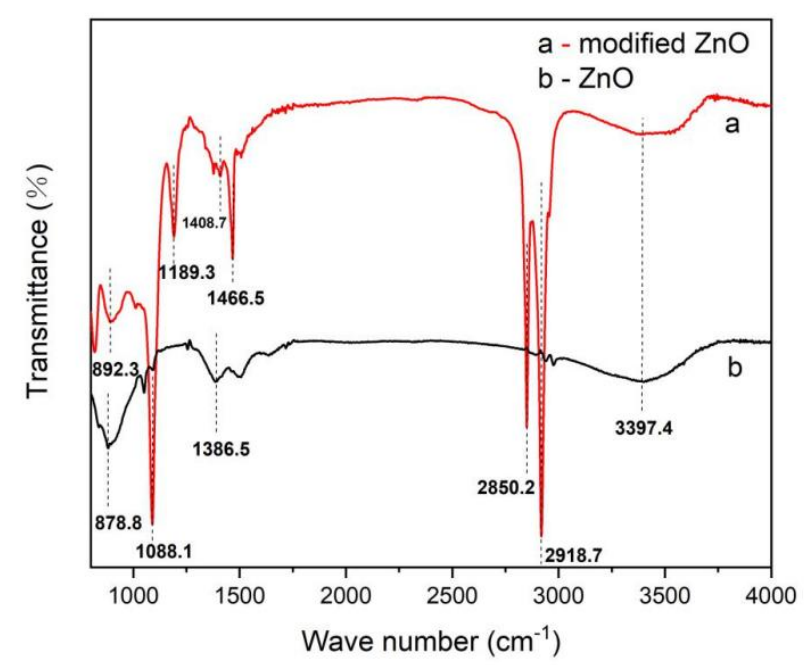

Figure 5. Infrared spectra of nano- $\mathrm{ZnO}$ before and after modification.

Compared with the FTIR spectrum of nano- $\mathrm{ZnO}$, several significant changes were observed in the spectrum of modified nano-ZnO. The peak at $1466.5 \mathrm{~cm}^{-1}$ resulted from the antisymmetric bending vibration of methyls and methylenes [34]. The new peak at $1189.3 \mathrm{~cm}^{-1}$ can be attributed to the vibration of the ester groups of the cross-linking agent. The peak at $2918.7 \mathrm{~cm}^{-1}$ was due to the stretching vibration of C-H bond (anti-symmetric vibration) in the $\mathrm{CH}_{3}$ unit, and the peak at $2850.2 \mathrm{~cm}^{-1}$ was due to the stretching vibration of C-H bond (symmetric vibration) in the $\mathrm{CH}_{3}$ unit. The peak at $1408.7 \mathrm{~cm}^{-1}$ was due to the in-plane bending vibration of $\mathrm{C}-\mathrm{H}$ bond. The peak at $892.3 \mathrm{~cm}^{-1}$ was due to the stretching vibration of $\mathrm{Zn}-\mathrm{O}-\mathrm{Si}$ bonds[z]. This is due to the hydrolysis of HDTMS, which converts $\mathrm{Si}-\mathrm{O}-\mathrm{CH}_{3}$ to $\mathrm{Si}-\mathrm{OH}$, and subsequently reacts with $-\mathrm{OH}$ on the surface of nano- $\mathrm{ZnO}$. The reaction equations are as follows:

$$
\begin{gathered}
\mathrm{ZnO}+\mathrm{H}_{2} \mathrm{O}=\mathrm{ZnO}-\mathrm{OH}+\mathrm{H} \\
\mathrm{CH}_{3}\left(\mathrm{CH}_{2}\right)_{15} \mathrm{Si}\left(\mathrm{OCH}_{3}\right)_{3}+3 \mathrm{H}_{2} \mathrm{O}=\mathrm{CH}_{3}\left(\mathrm{CH}_{2}\right)_{15} \mathrm{Si}(\mathrm{OH})_{3}+3 \mathrm{CH}_{3} \mathrm{OH} \\
3 \mathrm{ZnO}-\mathrm{OH}+\mathrm{CH}_{3}\left(\mathrm{CH}_{2}\right)_{15} \mathrm{Si}(\mathrm{OH})_{3}=\mathrm{CH}_{3}\left(\mathrm{CH}_{2}\right)_{15} \mathrm{Si}(\mathrm{OZn})_{3}+3 \mathrm{H}_{2} \mathrm{O}
\end{gathered}
$$

\subsection{XRD Analysis}

The XRD patterns of nano-ZnO with particle sizes of $30 \mathrm{~nm}$ and $90 \mathrm{~nm}$ are shown in Figure 6. Both patterns are consistent with the PDF standard files (JCPDS 36-1451), suggesting that nano- $\mathrm{ZnO}$ is a hexagonal crystalline. Moreover, no impurity peak was found in the patterns besides the characteristic peaks of $\mathrm{ZnO}$; therefore, the purchased $\mathrm{ZnO}$ had a high purity without the addition of impurity particles. The diffraction peaks were relatively high and narrow, especially for those of $90 \mathrm{~nm}$ nano- $\mathrm{ZnO}$, indicating that both nano-ZnO particles had good crystallinity. The calculation based on the full width at half height indicates that the particle size of $90 \mathrm{~nm}$ nano- $\mathrm{ZnO}$ was larger than the one with $30 \mathrm{~nm}$. 


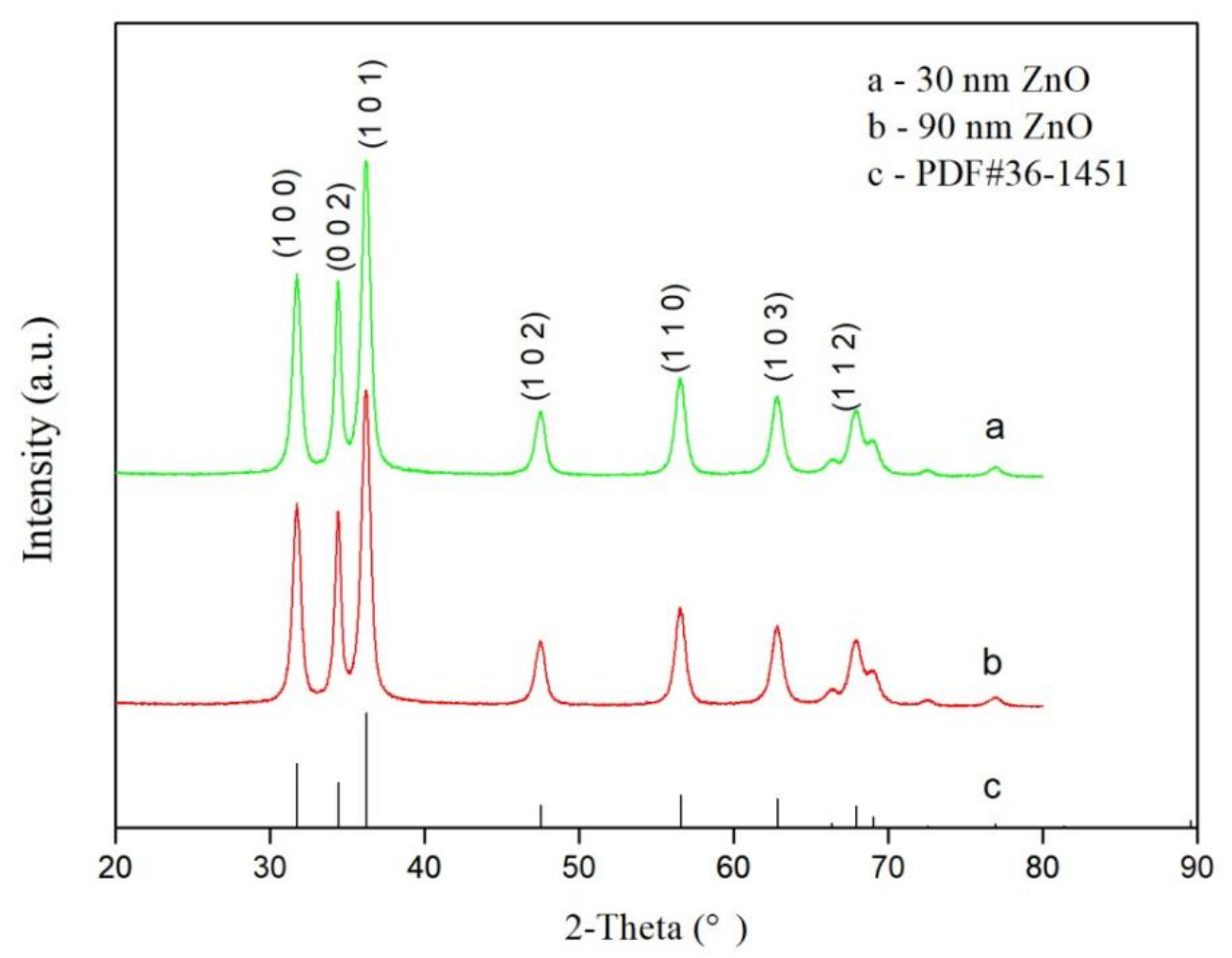

Figure 6. X-ray diffraction (XRD) patterns of nano-ZnO of two sizes.

\subsection{Morphology and EDS Analysis}

Figure 7 presents the FE-SEM images of the as-prepared superhydrophobic samples at various magnifications. The image at low magnification (Figure 7a) shows multiple small, coral-like lumps uniformly distributed on the surface of the superhydrophobic sample, suggesting that the spraying process was homogeneous across the substrate surface. At a high magnification (Figure 7c), the shape of $\mathrm{ZnO}$ particles was flake-like, which can be found on the surface of acrylic resin, embedded into the resin, or wrapped by the resin. The abundant fine pores on the surface with a good roughness are favorable for hydrophobicity. Figure 8. shows the EDS result of the as-prepared superhydrophobic sample. The elements found on the surface were $\mathrm{C}, \mathrm{O}, \mathrm{Zn}, \mathrm{Ca}$, and a small amount of $\mathrm{Si}$. The origin of $\mathrm{Ca}$ in the EDS diagram is the presence of the $\mathrm{CaCO}_{3}$, as the filler in acrylic resin. The result agrees with the content of HDTMS used for the modification of $\mathrm{ZnO}$, further indicating the successful grafting of HDTMS on the surface of $\mathrm{ZnO}$.
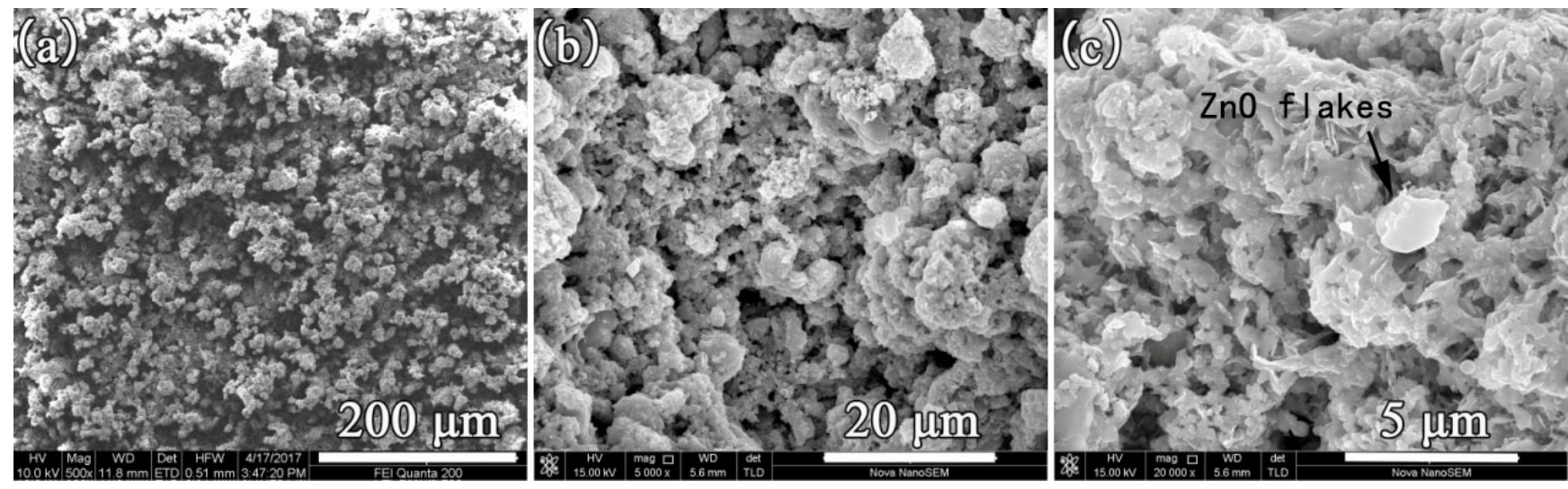

Figure 7. FE-scanning electron microscopy (SEM) image of a sample at different magnifications. (a): 500×; (b):5000× (c): $20,000 \times$. 


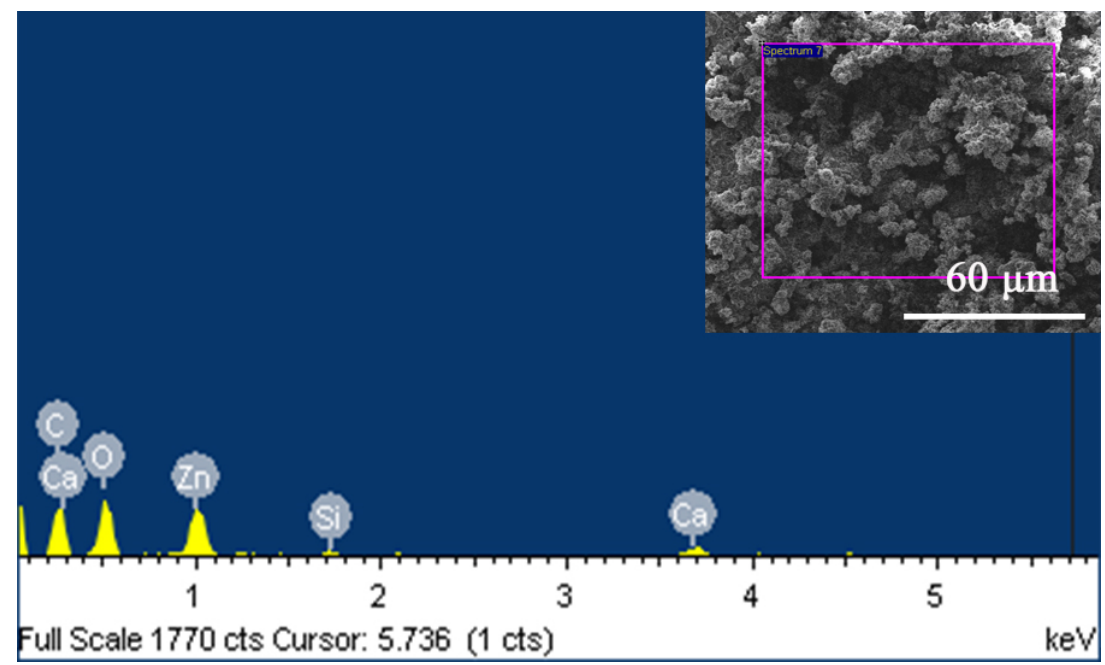

Figure 8. EDS diagram of superhydrophobic samples.

\subsection{Cross-Section Morphology}

The cross-sectional SEM image of the as-prepared superhydrophobic sample is shown in Figure 9. A clear three-layered structure was found on the cross-section. The upper layer with the thickness of $106 \mu \mathrm{m}$ was a mixture of nano- $\mathrm{ZnO}$ and acrylic resin decorated with several fine particles, signifying a relatively high roughness. The medium layer with the thickness of $60.32 \mu \mathrm{m}$ was the primer and significantly smoother than the upper layer. The lower layer was aluminum sheet and all three layers displayed good binding with each other.

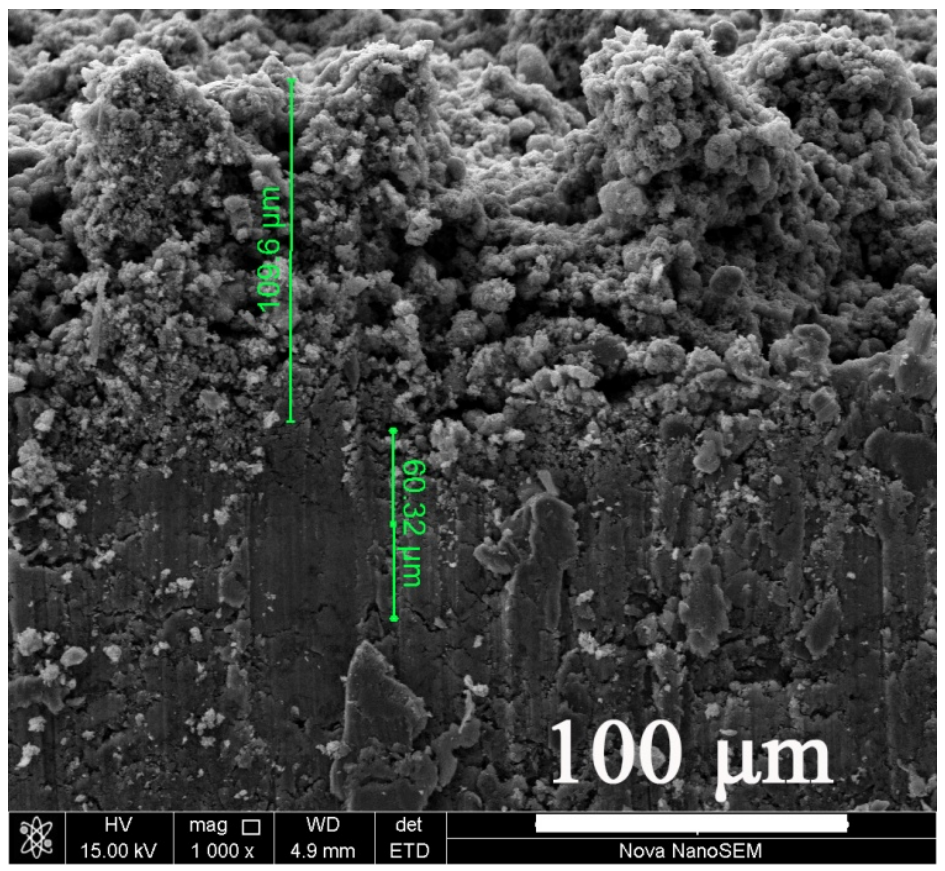

Figure 9. SEM cross-sectional image of a superhydrophobic sample.

\subsection{Effect of Surfactant on Hydrophobicity}

The change in surface wettability of the samples modified with various mass fractions of HDTMS is presented in Figure 10. The mass ratio of acrylic resin to nano- $\mathrm{ZnO}$ was maintained at 1:4. With the increase in HDTMS content, the contact angle of the sample increased while the sliding angle decreased. Without the addition of a surfactant, the contact angle was merely $37.21^{\circ}$. When the HDTMS content increased to $10 \%$, the improve- 
ment reached the highest point with a contact angle of $168.11^{\circ}$ and a sliding angle of $7.2^{\circ}$. However, the sliding angle was still relatively high as a high surface roughness leads to a lag in the variation of sliding angles.

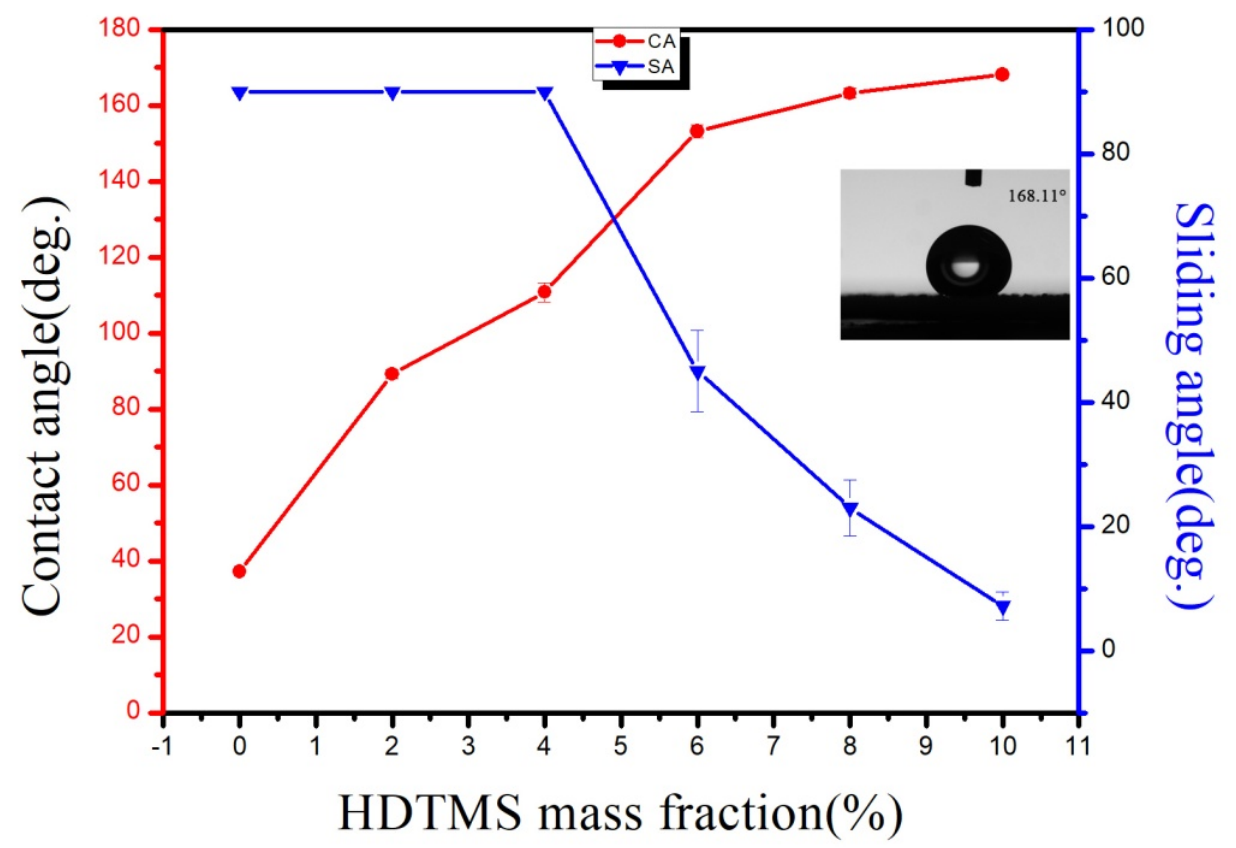

Figure 10. Wettability of samples modified with different mass fractions of HDTMS.

\subsection{Effect of Weight Ratio of Acrylic Resin to $\mathrm{ZnO}$ on Hydrophobicity}

The effect of the weight ratio of acrylic resin to $\mathrm{ZnO}$ on hydrophobicity is shown in Figure 11. At the ratio of 0.5:2, the contact and sliding angles of the sample were $168.11^{\circ}$ and $7.2^{\circ}$, respectively. When the ratio increased to $3: 2$, the contact angle decreased to $162.54^{\circ}$ while the sliding angle increased to $86^{\circ}$. The angle variations indicate that the hydrophobicity of the sample was reduced with the increase in acrylic resin because the modified nano- $\mathrm{ZnO}$ was more wrapped with resin. The exposed surface of nano- $\mathrm{ZnO}$ was reduced; hence, the hydrophobicity decreased [35]. When the ratio of acrylic resin to $\mathrm{ZnO}$ is $3: 2$, there is a sharp increase in the sliding angle, the main reason being that, with the increase of resin content, more nano $\mathrm{ZnO}$ particles are wrapped by resin, resulting in the decrease of exposed nano $\mathrm{ZnO}$ particles, and then leading to the decrease of hydrophobicity and the increase of sliding angle.

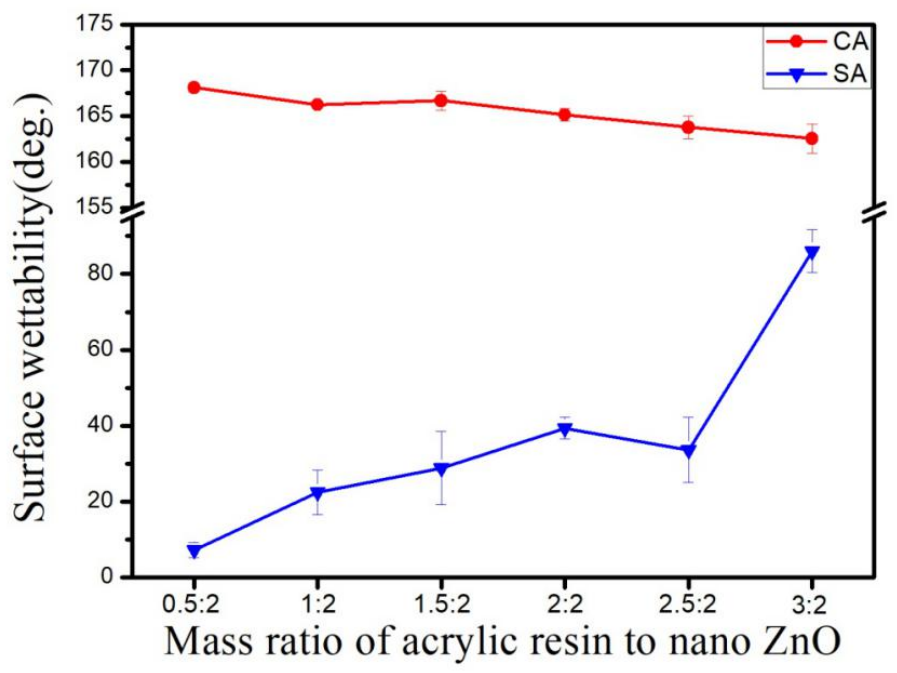

Figure 11. Sample wettability of different acrylic resin-to- $\mathrm{ZnO}$ mass ratio. 


\subsection{Wear Resistance}

Figure 12 presents the relationship between the times of sanding and wettability of the samples prepared by various mass ratios of resin to $\mathrm{ZnO}$. As shown in Figure 12, with the increase of the friction times, the hydrophobicity of all the six samples decreased, but with different downward trends. A greater decrease was found in the sample with a lower ratio of acrylic resin. With higher content of acrylic resin, there was only a slight downward trend in hydrophobicity. This is because, with larger ratios of resin, the binding force within resin was stronger, which can lead to formation of a network structure, enhancing wear resistance in the process. All the samples shown in Figure 12 were only sanded 10 times and the contact angle was already decreased to $146.06^{\circ}$, which cannot meet the requirement of superhydrophobicity. Figure 13 presents the SEM image of the sample prepared with a resin-to- $\mathrm{ZnO}$ ratio of 1:4 after sanding 10 times. The particles on the surface were mostly exfoliated and only a small number of $\mathrm{ZnO}$ particles were found on the surface. Nano- $\mathrm{ZnO}$ inhibits resin forming films, which increases the interstices between molecules, causing the binding strength of resin to decrease. Hence, the surface shows poorer wear resistance, leading to a reduction in roughness and hydrophobicity [35].

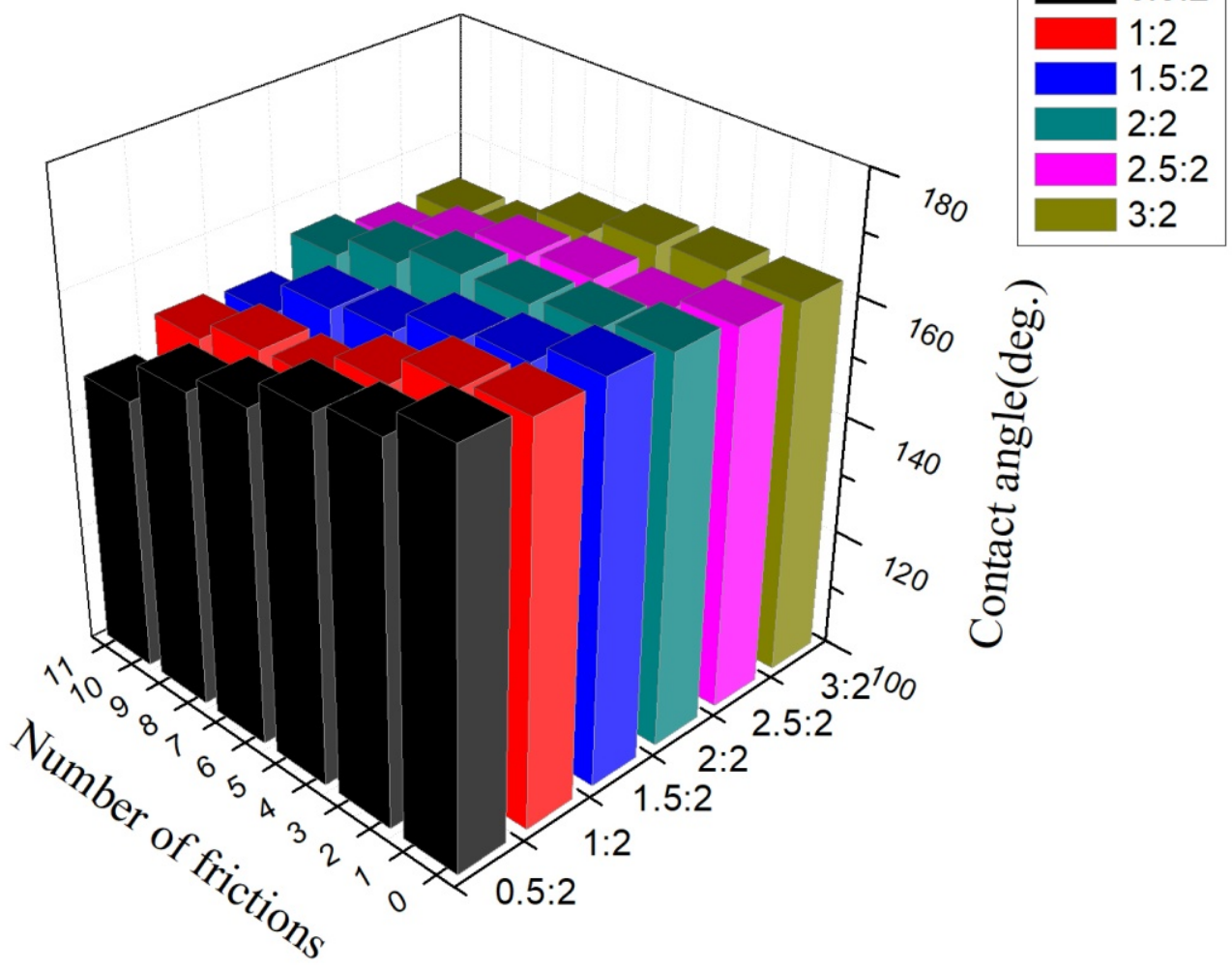

Figure 12. Relationship between the number of frictions and wettability of samples prepared with various mass ratios of resin to $\mathrm{ZnO}$.

\subsection{Antibacterial Properties}

The antibacterial properties of the superhydrophobic sample and comparison samples were analyzed based on the standard method for inorganic nanomaterials [36]. The comparison sample was the pure acrylic resin coating. The colony counts after the bacterial inoculation on the sample surface are listed in Table 1. The results indicate that the antibacterial rate of the superhydrophobic sample was $100 \%$, while that of the comparison sample was 0 . The antibacterial data suggest that the superhydrophobic nano- $\mathrm{ZnO} /$ acrylic resin coating possesses excellent antibacterial properties, while the pure acrylic resin coating hardly had this property. This is owing to the dissolving $\mathrm{Zn}^{2+}$ ions on the surface of the superhydrophobic nano-ZnO/acrylic resin coating, which can damage the bacterial structure. 
Meanwhile, the superhydrophobic coating can shield water because of the air-containing layer, reducing the adhesion of bacterial proteins on the surface and partly contributing to the antibacterial properties of superhydrophobic coating. Therefore, the antibacterial behavior of the nano- $\mathrm{ZnO} /$ acrylic resin superhydrophobic coating can be accredited to the coupling effect of the dissolved $\mathrm{Zn}^{2+}$ ions and the superhydrophobic insulation $[36,37]$. The superhydrophobicity of the surface is usually covered with organic film, which will greatly improve the hydrophobicity of the surface of the material. However, the film formed by organic matter is often of poor mechanical strength, and high temperature or external force wear will lead to the damage of organic film. Thus, surface superhydrophobicity and mechanical stability are mutually exclusive properties for the organic/inorganic hybrid. The development or adoption of new organic resin materials may be one of the trends in the future.
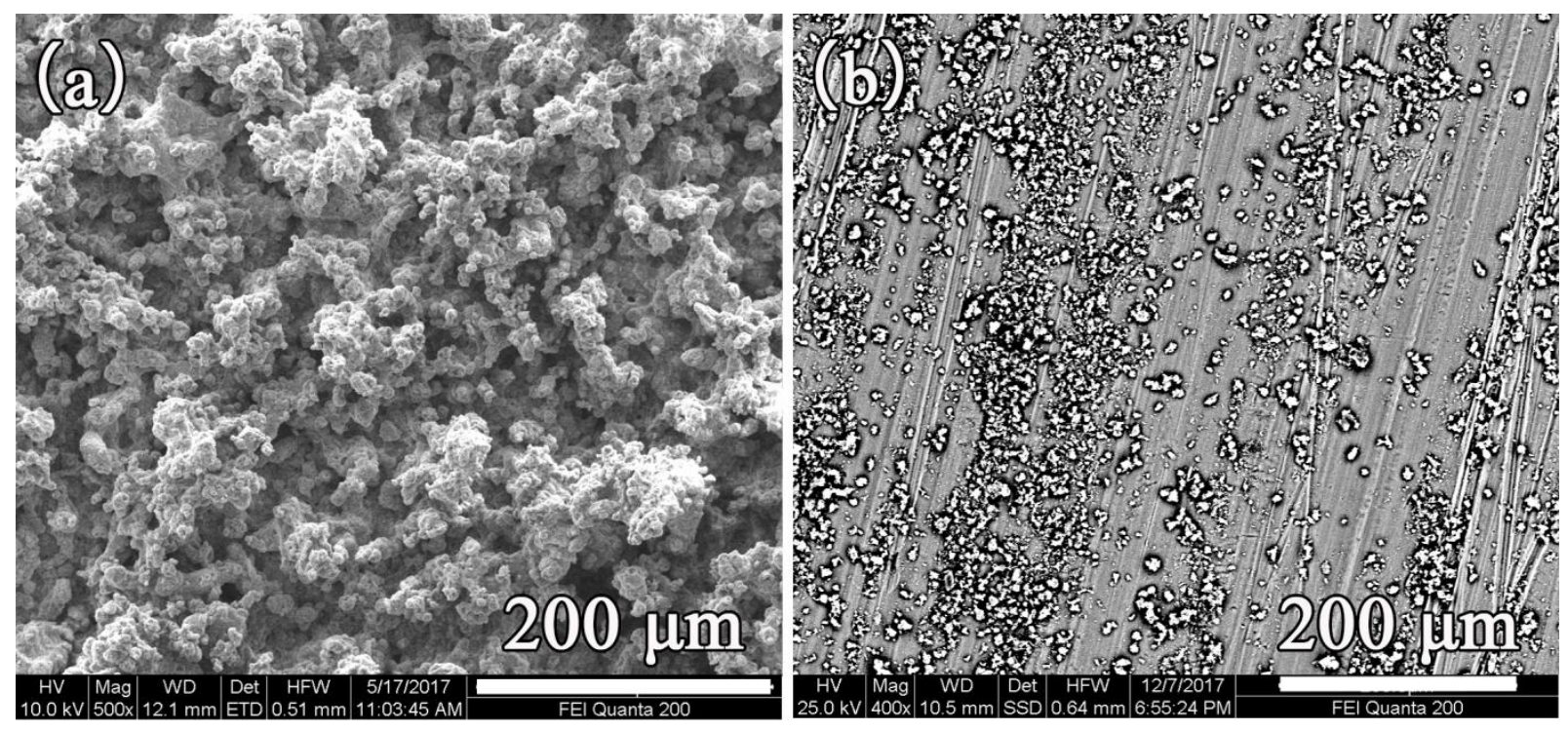

Figure 13. SEM image of sample prepared with resin-to-ZnO ratio of 1:4 (a) before and (b) after sanding 10 times.

Table 1. Antibacterial properties of nano-ZnO/acrylic resin and pure acrylic resin.

\begin{tabular}{ccc}
\hline Sample & Colony Counts & Antibacterial Rate \\
\hline nano-ZnO/acrylic resin superhydrophobic coating & 0 & $100 \%$ \\
Comparison sample (pure acrylic resin coating) & 57 & 0 \\
\hline
\end{tabular}

\section{Conclusions}

The as-prepared nano-ZnO/acrylic resin superhydrophobic coating possessed a good hydrophobicity. The morphological characterization shows that the micro/nano structure of the composite was uniformly distributed on the sample surface, suggesting that the spraying process was homogeneous. The preparation method is simple and can be suitable for large-scale manufacturing. The effect of the surfactant content and the mass ratio of acrylic resin to nano- $\mathrm{ZnO}$ on the hydrophobicity of the coating was studied. When the surfactant content was $10 \mathrm{wt} \%$ and the ratio of acrylic resin to nano- $\mathrm{ZnO}$ was $1: 4$, and the hydrophobicity was the best with contact and rolling angles of $168.11^{\circ}$ and 7.2 , respectively. The wear resistance test of the coatings with various acrylic resin ratios showed that the wear resistance was insufficient with a low resin content and increased with the resin content. However, the hydrophobicity of the coating decreased when the resin content was excessive owing to the wrapping of nano- $\mathrm{ZnO}$ by the resin, which reduced the number of hydrophobic groups on the surface and worsened the hydrophobicity of the coating. The antibacterial tests showed that, compared with the pure acrylic resin coating, the superhydrophobic nano- $\mathrm{ZnO} /$ acrylic resin coating possessed superb antibacterial properties. 
Author Contributions: Original draft of the manuscript, C.L.; Formal analysis, C.W.; Funding acquisition, Z.L.; Investigation, Z.C.; Methodology, Y.X., Z.L.; Software, M.X.; Writing-review \& editing, J.Z. supervision, J.Z. All authors have read and agreed to the published version of the manuscript.

Funding: This work was financially supported by the National Natural Science Foundation of China (Nos. 51602142, 51662032 and 21667019), the Key Project of Natural Science Foundation of Jiangxi Province (Nos. 20171ACB20016 and 20202ACBL214009), the Jiangxi Province Major Academic and Technical Leaders Cultivating Object Program (No. 20172BCB22014), the Science and Technology Department of Jiangxi Province (Nos. 20151BAB216010, 20181BCB18003 and 20181ACG70025), and the Key Project of Science and Technology Research of the Jiangxi Provincial Department of Education (Nos. DA201601034, DA201602063 and GJJ191044), the Aviation Science Foundation of China (No. 2017ZF56020), and Fujian Key Laboratory of Measurement and Control System for of Shore Environment (No. S1-KF1703).

Institutional Review Board Statement: Not applicable.

Informed Consent Statement: Not applicable.

Data Availability Statement: All the data is available within the manuscript.

Conflicts of Interest: The authors declare no conflict of interest.

\section{References}

1. Lejars, M.; Margaillan, A.; Bressy, C. Fouling release coatings: A nontoxic alternative to biocidal antifouling coatings. Chem. Rev. 2012, 112, 4347-4390. [CrossRef]

2. Chen, Z.F.; Zhao, W.J.; Xu, J.H.; Mo, M.T.; Peng, S.S.; Zeng, Z.X.; Wu, X.D.; Xue, Q.J. Designing enyironmentally benign modified silica resign coatings with biomimetic textures for antibiofouling. RSC Adv. 2015, 5, 36874-36881. [CrossRef]

3. Yao, L.; He, J. Recent progress in antireflection and self-cleaning technology from surface engineering to functional surfaces. Prog. Mater. Sci. 2014, 61, 94-143. [CrossRef]

4. Yuan, Z.Q.; Chen, H.; Zhang, J.D.; Zhao, D.J.; Liu, Y.J.; Zhou, X.Y.; Song, L.; Shi, P.; Tang, J.X.; Chen, X. Preparation and characterization of self-cleaning stable superhydrophobic linear low-density polyethylene. Sci. Technol. Adv. Mater. 2008, 9, 045007. [CrossRef] [PubMed]

5. Liu, H.Q.; Szunerits, S.; Xu, W.G.; Boukherroub, R. Preparation of superhydrophobic coatings on zinc as effective corrosion barriers. ACS Appl. Mater. Inter. 2009, 1, 1150-1153. [CrossRef] [PubMed]

6. Long, Y.F.; Yin, X.X.; Mu, P.; Wang, Q.T.; Hu, J.J.; Li, J. Slippery liquid-infused porous surface (SLIPS) with superior liquid repellency, anti-corrosion, anti-icing and intensified durability for protecting substrates. Chem. Eng. J. 2020, 401, 126137. [CrossRef]

7. Zhang, J.; Seeger, S. Polyester materials with superwetting silicone nanofilaments for oil/water separation and selective oil absorption. Adv. Funct. Mater. 2011, 21, 4699-4700. [CrossRef]

8. Hu, Z.F.; Wu, X.M.; Chu, F.Q.; Zhang, X.; Yuan, Z.P. Off-centered droplet impact on single-ridge superhydrophobic surfaces. Exp. Therm. Fluid Sci. 2021, 120, 110245. [CrossRef]

9. Callow, J.A.; Callow, M.E. Trends in the development of environmentally friendly fouling-resistant marine coatings. Nat. Commun. 2011, 2, 803-814. [CrossRef]

10. Pernites, R.B.; Santos, C.M.; Maldonado, M.; Ponnapati, R.R.; Rodrigues, D.F.; Advincula, R.C. Tunable protein and bacterial cell adsorption on colloidally templated superhydrophobic polythiophenefilms. Chem. Mater. 2011, 24, 870-880. [CrossRef]

11. Zhao, J.; Song, L.J.; Yin, J.H.; Ming, W.H. Anti-bioadhesion on hierarchically structured, superhydrophobic surfaces. Chem. Commun. 2013, 49, 9191-9193. [CrossRef] [PubMed]

12. Mahalakshmi, P.V.; Vanithakumari, S.C.; Gopal, J.; Mudali, U.K.; Raj, B. Enhancing corrosion and biofouling resistance through superhydrophobic surface modification. Curr. Sci. India. 2011, 101, 1328-1336.

13. Wang, Z.H.; Zuilhof, H. Self-healing superhydrophobic fluoropolymer brushes as highly protein-repellent coatings. Langmuir 2016, 32, 6310-6318. [CrossRef] [PubMed]

14. Mishra, G.; Mittal, N.; Sharma, A. Multifunctional mesoporous carbon capsules and their robust coatings for encapsulation of actives: Antimicrobial and anti-bioadhesion functions. ACS Appl. Mater. Interfaces 2017, 9, 19371-19379. [CrossRef]

15. Greene, G.W.; Ortiz, V.; Pozo-Gonzalo, C.; Moulton, S.E.; Wang, X.; Martin, L.L.; Michalczky, A.; Howlett, P.C. Lubricin antiadhesive coatings exhibit size-selective transport properties that inhibit biofouling of electrode surfaces with minimal loss in electrochemical activity. Adv. Mater. Interfaces 2018, 5, 1701296. [CrossRef]

16. Li, Y.C.; Xu, Y.L.; Fleischer, C.C.; Huang, J.; Lin, R.; Yang, L.; Mao, H. Impact of anti-biofouling surface coatings on the properties of nanomaterials and their biomedical applications. J. Mater. Chem. B 2018, 6, 9-24. [CrossRef]

17. Fan, L.; Li, B.; Zhang, J. Antibioadhesive superhydrophobic syringe needles inspired by mussels and lotus leafs. Adv. Mater. Interfaces 2015, 2, 1500019. [CrossRef]

18. Dou, X.Q.; Zhang, D.; Feng, C.L.; Jiang, L. Bioinspired hierarchical surface structures with tunable wettability for regulating bacteria adhesion. ACS Nano 2015, 9, 10664-10672. [CrossRef] 
19. Jin, C.F.; Jiang, Y.F.; Niu, T.; Huang, J.G. Cellulose-based material with amphiphobicity to inhibit bacterial adhesion by surface modification. J. Mater. Chem. 2012, 22, 12562-12567. [CrossRef]

20. Emelyanenko, K.A.; Zulkarneev, E.R.; Kiseleva, I.A.; Vasiliev, A.L.; Emelyanenko, A.M. Effective antibacterial nanotextured surfaces based on extreme wettability and bacteriophage seeding. ACS Appl. Nano. Mater. 2018, 1, 1348-1359.

21. Spasova, M.; Manolova, N.; Markova, N.; Rashkov, I. Superhydrophobic PVDF and PVDF-HFP nanofibrous mats with antibacterial and anti-biofouling properties. Appl. Surf. Sci. 2016, 363, 363-371. [CrossRef]

22. Marmur, A. Underwater superhydrophobicity: Theoretical feasibility. Langmuir 2006, 22, 1400-1402. [CrossRef] [PubMed]

23. Wang, F.J.; Lei, S.; Ou, J.F.; Xue, M.S.; Li, W. Superhydrophobic surface with excellent mechanical durability and easy repairability. Appl. Surf. Sci. 2013, 276, 397-400. [CrossRef]

24. Li, C.Q.; Xie, C.; Ou, J.F.; Xue, M.S.; Wang, F.J.; Lei, S.; Fang, X.Z.; Zhou, H.Y.; Li, W. ZnO superhydrophobic coating via convenient spraying and its biofouling resistance. Surf. Interface Anal. 2018, 50, 1278-1285. [CrossRef]

25. Li, C.Q.; Zhan, Y.L.; Lei, S.; Li, W. Preparations of superhydrophobic surfaces using the one-step spin coating method and characterizations of their anti-icing behavior. Int. J. Mater. Res. 2019, 110, 1135-1141. [CrossRef]

26. Hsieh, C.T.; Chen, J.M.; Kuo, R.R.; Lin, T.S.; Wu, C.F. Influence of surface roughness on water-and oil-repellent surfaces coated with nanoparticles. Appl. Surf. Sci. 2005, 240, 318-326. [CrossRef]

27. Tran, N.G.; Chun, D. Green manufacturing of extreme wettability contrast surfaces with superhydrophilic and superhydrophobic patterns on aluminum. J. Mater. Process. Technol. 2021, 297, 117-245. [CrossRef]

28. Usman, J.; Othman, M.H.D.; Ismail, A.F.; Rahman, M.A.; Jaafar, J.; Raji, Y.O.; Gbadamosi, A.O.; El Badawy, T.H.; Said, K.A.M. An overview of superhydrophobic ceramic membrane surface modification for oil-water separation. J. Mater. Res. Technol. 2021, 12, 643-667. [CrossRef]

29. Shaban, M.; Mohamed, F.; Abdallah, S. Production and characterization of superhydrophobic and antibacterial coated fabrics utilizing ZnO Nanocatalyst. Sci. Rep. 2018, 8, 3925. [CrossRef] [PubMed]

30. Song, X.Y.; Zhai, J.; Wang, Y.L.; Jiang, L. Self-assembly of amino-functionalized monolayers on silicon surfaces and preparation of superhydrophobic surfaces based on alkanoic acid dual layers and surface roughening. J. Colloid. Interf. Sci. 2006, 298, 267-273. [CrossRef] [PubMed]

31. Guo, M.; Diao, P.; Cai, S. Highly hydrophilic and superhydrophobic ZnO nanorod array films. Thin Solid Film. 2007, 515, 7162-7166. [CrossRef]

32. Sakai, M.; Kono, H.; Nakajima, A.; Zhang, X.T.; Sakai, H.; Abe, M.; Fujishima, A. Sliding of water droplets on the superhydrophobic surface with ZnO nanorods. Langmuir 2009, 25, 14182-14186. [CrossRef] [PubMed]

33. Gong, A.; Zheng, Y.; Yang, Z. Spray fabrication of superhydrophobic coating on aluminum alloy for corrosion mitigation. Mater. Today Commun. 2021, 26, 101828. [CrossRef]

34. Lee, D.; Park, D.; Shin, K.; Seo, H.M.; Lee, H.; Choi, Y.; Kim, J.W. ZnO nanoparticles-laden cellulose nanofibers-armored Pickering emulsions with improved UV protection and water resistance. J. Ind. Eng. Chem. 2021, 96, 219-225. [CrossRef]

35. Uzoma, P.C.; Liu, F.; Xu, L.; Zhang, Z.C.; Han, E.H.; Ke, W.; Arukalam, I.O. Superhydrophobicity, conductivity and anticorrosion of robust siloxane-acrylic coatings modified with graphene nanosheets. Prog. Org. Coat. 2019, 127, 239-251. [CrossRef]

36. Wang, T.; Lu, Z.; Wang, X.Q.; Zhang, Z.; Zhang, Q.; Yan, B.; Wang, Y. A compound of ZnO/PDMS with photocatalytic, self-cleaning and antibacterial properties prepared via two-step method. Appl. Surf. Sci. 2021, 550, 149286. [CrossRef]

37. Xie, C.; Li, C.Q.; Xie, Y.; Cao, Z.; Li, S.Q.; Zhao, J.S.; Wang, M. ZnO/Acrylic polyurethane nanocomposite superhydrophobic coating on aluminum substrate obtained via spraying and Co-Curing for the control of marine biofouling. Surf. Interfaces 2021, 22, 100833. [CrossRef] 